\title{
Multiple-responsive dendronized hyperbranched polymers
}

\author{
Xiacong Zhang, Ting Liu, Jiatao Yan, Kun Liu, Wen Li * and Afang Zhang *
}

Laboratory of Polymer Chemistry, School of Materials Science and Engineering, Shanghai University,

Materials Building Room 801, Nanchen Street 333, Shanghai 200444, China.

\section{Table of Content}

Scheme S1. Reagents and conditions

Figure S1. Normalized refractive index traces from gel permeation chromatography of P1, P2 and

P3. .S2

Figure S2. ${ }^{1} \mathrm{H}$ NMR of P1, P2 and P3 in DMSO- $d_{6}$.

Figure S3. a) Plots of transmittance vs temperature for aqueous solutions of P1 with different concentrations. b) Plots of polymer concentration vs cloud points for $\mathrm{P} 1$ in $\mathrm{pH} 7.0$ buffer solutions. Heating rate $=0.5^{\circ} \mathrm{C} \cdot \mathrm{min}^{-1}$.

Figure S4. a) Plots of transmittance vs temperature for $\mathrm{P} 1$ in $\mathrm{pH} 7.0$ buffer solutions with different heating rate. Polymer concentration $=0.1 \mathrm{wt} \%$. b) Plots of transmittance vs temperature for $\mathrm{P} 1$ in $\mathrm{pH} 7.0$ buffer solutions during heating and cooling process. Polymer concentration $=0.1 \mathrm{wt} \%$, heating rate $=0.5^{\circ} \mathrm{C} \cdot \mathrm{min}^{-1}$

Figure S5. Plots of transmittance vs temperature for 0.25 wt\% aqueous solutions of P1,(a) P2, (b) P3 (c) at different $\mathrm{pH}$. Heating rate $=0.5^{\circ} \mathrm{C} \cdot \mathrm{min}^{-1}$. S4

Figure S6. ${ }^{1} \mathrm{H}$ NMR spectra of the model compound formed from monoaldehyde carrying OEGdendron and triacylhydrazone $\mathrm{B}_{3}$ in $\mathrm{D}_{2} \mathrm{O}$ solution at different $\mathrm{pH}$.

Figure S7. Cytotoxicity of P1, P2 and P3 in HeLa cell line by CCK-8 assay. Data are mean values plus/minus standard deviation of six samples/cultures.....................................S4

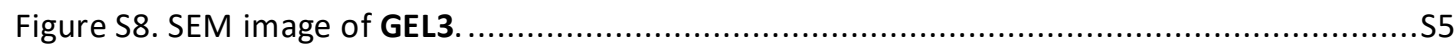

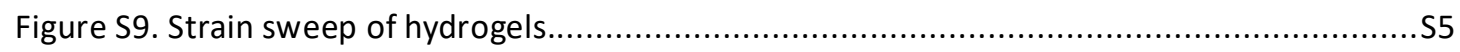

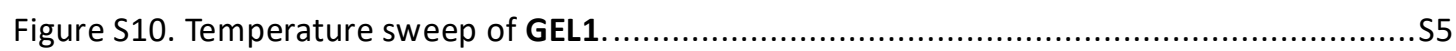

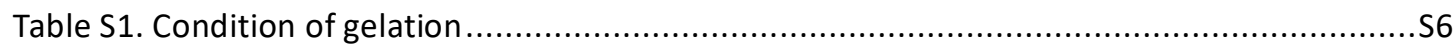

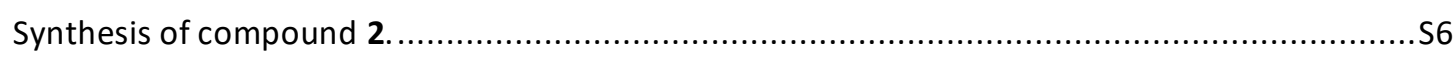

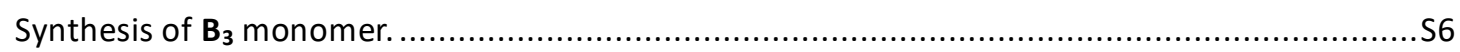




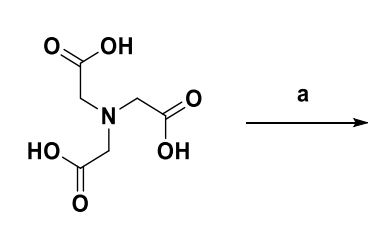

1

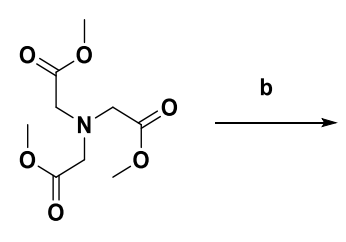

2

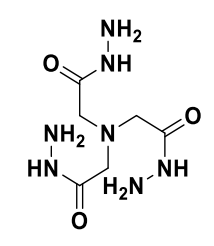

$B_{3}$

Scheme S1. Reagents and conditions: (a) $\mathrm{SOCl}_{2}, \mathrm{MeOH}(52 \%)$; (b) hydrazine hydrate, $\mathrm{MeOH}(99 \%)$.

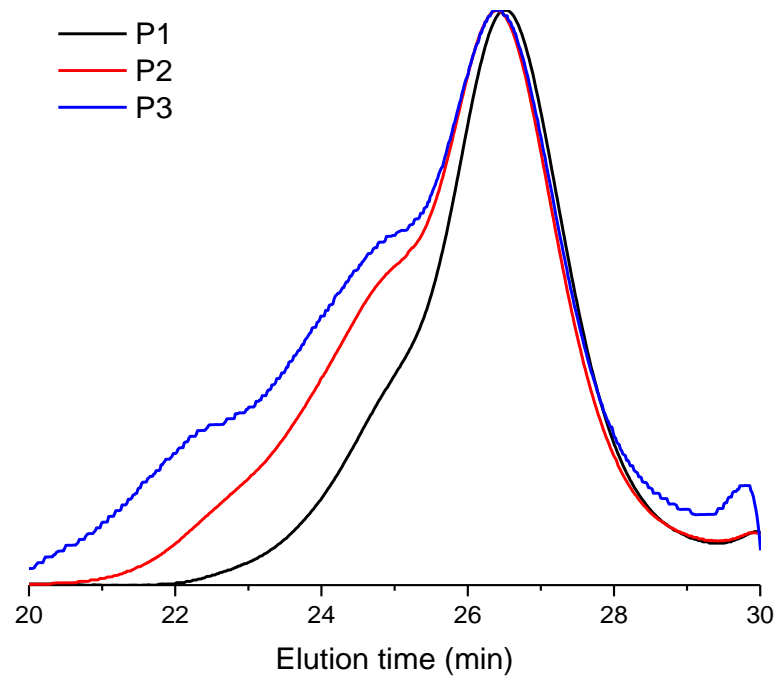

Figure S1. Normalized refractive index traces from gel permeation chromatography of P1, P2 and P3.

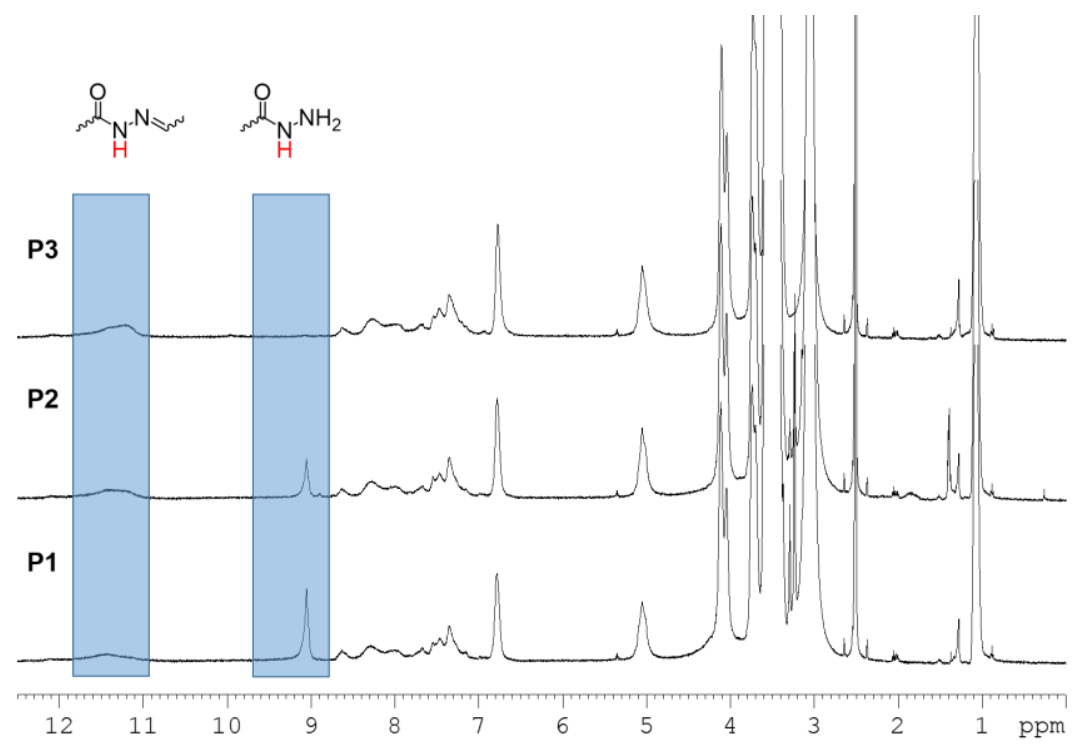

Figure $\mathrm{S} 2 .{ }^{1} \mathrm{H}$ NMR of P1, $\mathbf{P 2}$ and $\mathbf{P 3}$ in DMSO- $d_{6}$. 

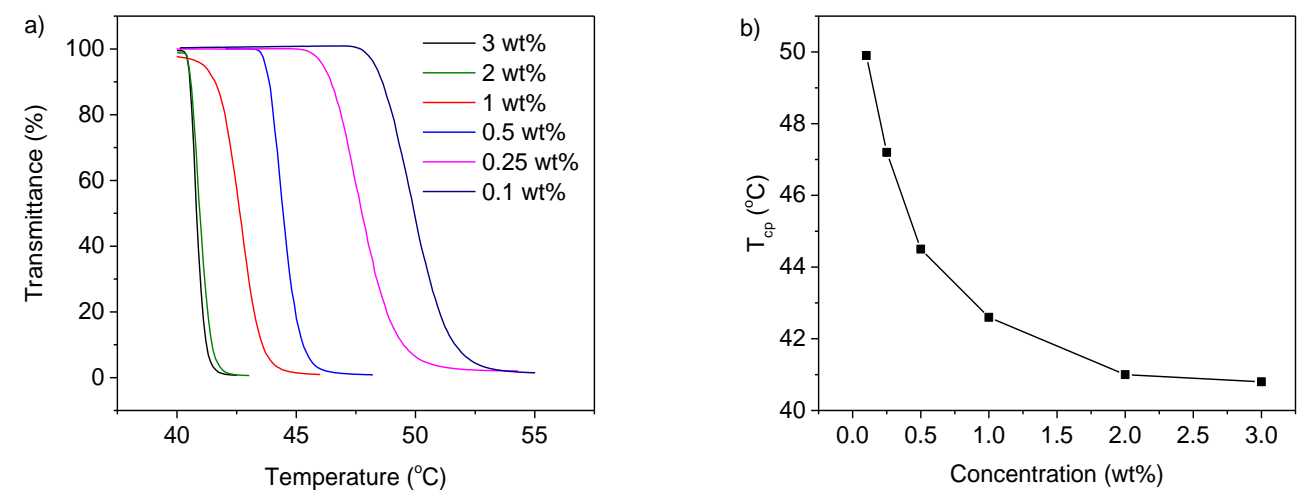

Figure S3. a) Plots of transmittance vs temperature for aqueous solutions of $\mathrm{P} 1$ with different concentrations. b) Plots of polymer concentration vs cloud points for $\mathrm{P} 1 \mathrm{in} \mathrm{pH} 7.0$ buffer solutions. Heating rate $=0.5^{\circ} \mathrm{C} \cdot \mathrm{min}^{-1}$.
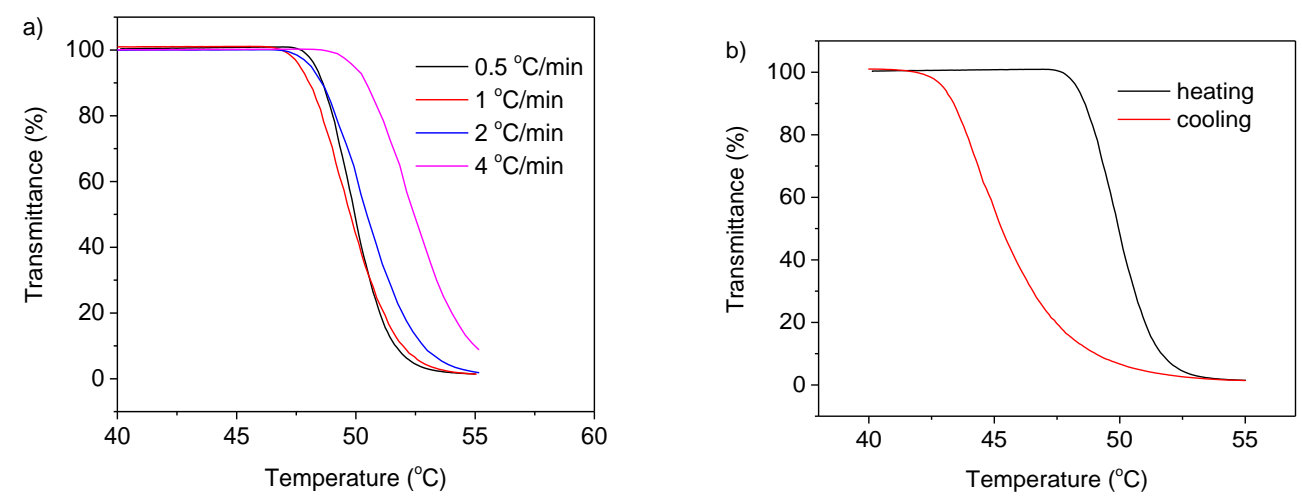

Figure S4. a) Plots of transmittance vs temperature for $\mathrm{P} 1$ in $\mathrm{pH} 7.0$ buffer solutions with different heating rate. Polymer concentration $=0.1 \mathrm{wt} \%$. b) Plots of transmittance vs temperature for $\mathrm{P} 1$ in $\mathrm{pH} 7.0$ buffer solutions during heating and cooling process. Polymer concentration $=0.1 \mathrm{wt} \%$, heating rate $=0.5^{\circ} \mathrm{C} \cdot \mathrm{min}^{-1}$.

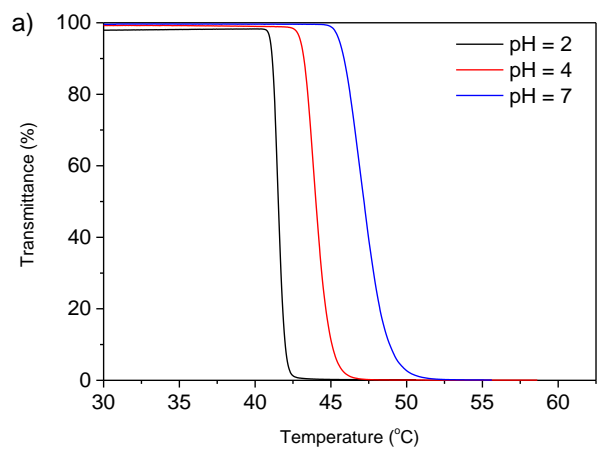



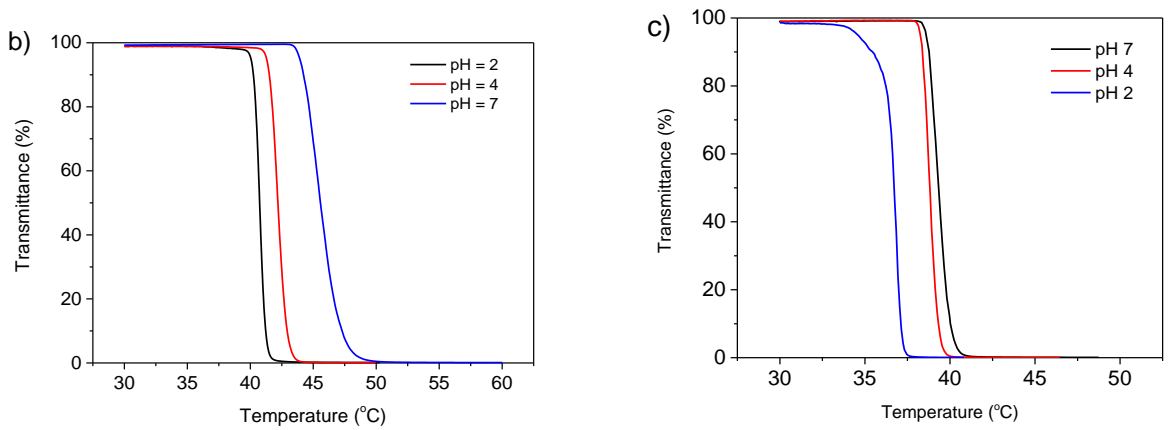

Figure S5. Plots of transmittance vs temperature for 0.25 wt\% aqueous solutions of P1,(a) P2, (b) P3 (c) at different $\mathrm{pH}$. Heating rate $=0.5^{\circ} \mathrm{C} \cdot \mathrm{min}^{-1}$.

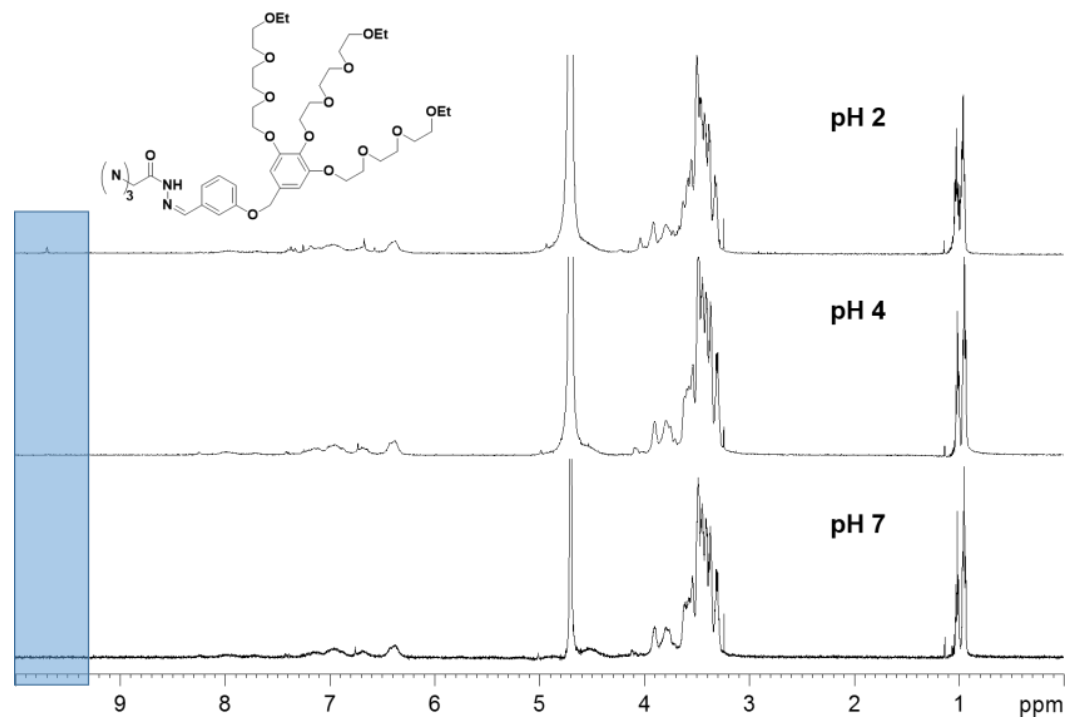

Figure S6. ${ }^{1} \mathrm{H}$ NMR spectra of the model compound formed from monoaldehyde carrying OEGdendron and triacylhydrazone $\mathrm{B}_{3}$ in $\mathrm{D}_{2} \mathrm{O}$ solution at different $\mathrm{pH}$.

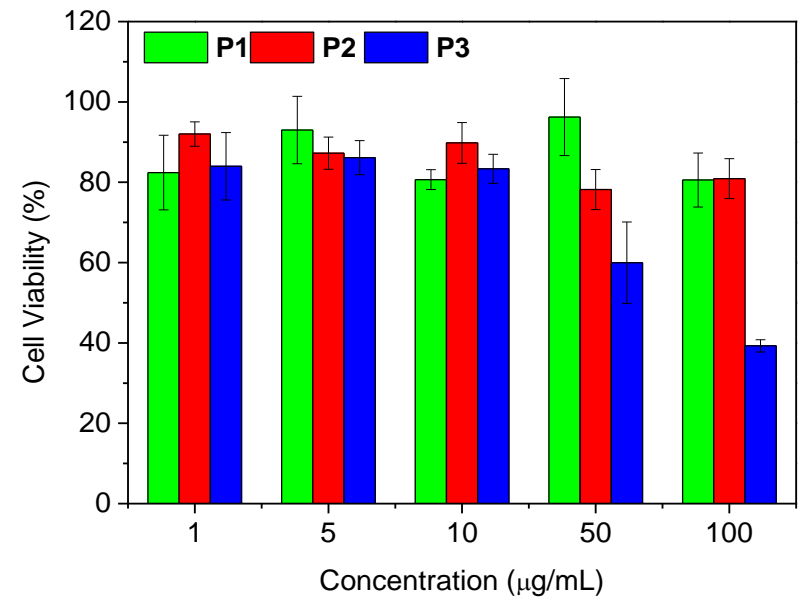

Figure S7. Cytotoxicity of P1, P2 and P3 to HeLa cell line by CCK-8 assay. Data are mean values plus/minus standard deviation of six samples/cultures. 


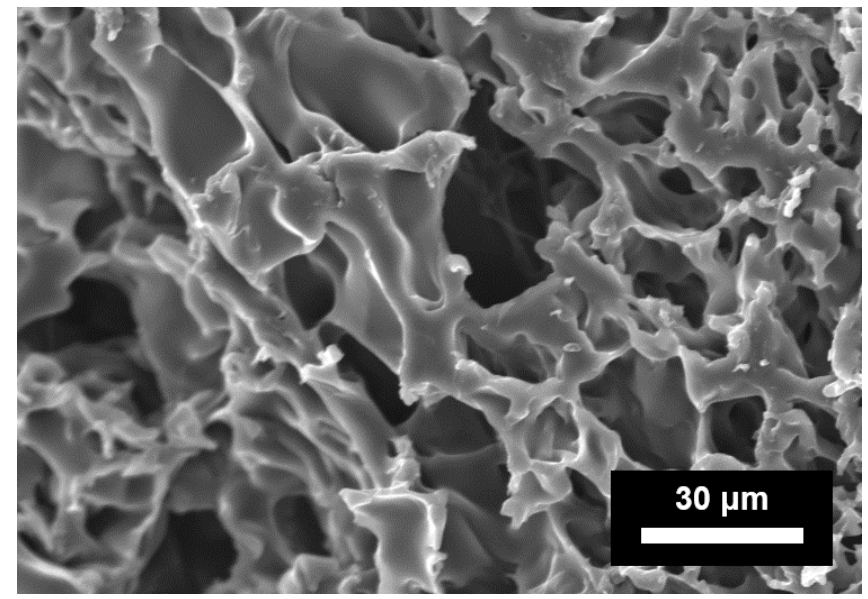

Figure S8. SEM image of GEL3.

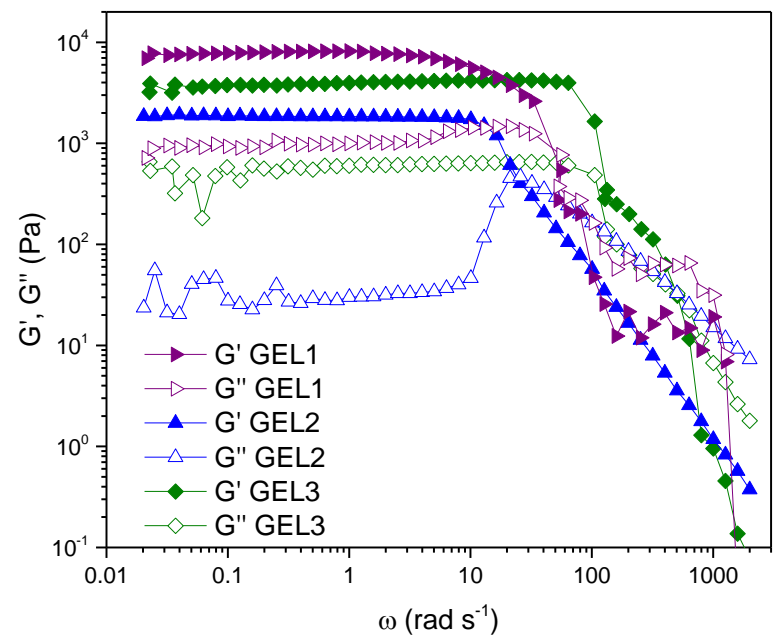

Figure S9. Strain sweep of hydrogels.

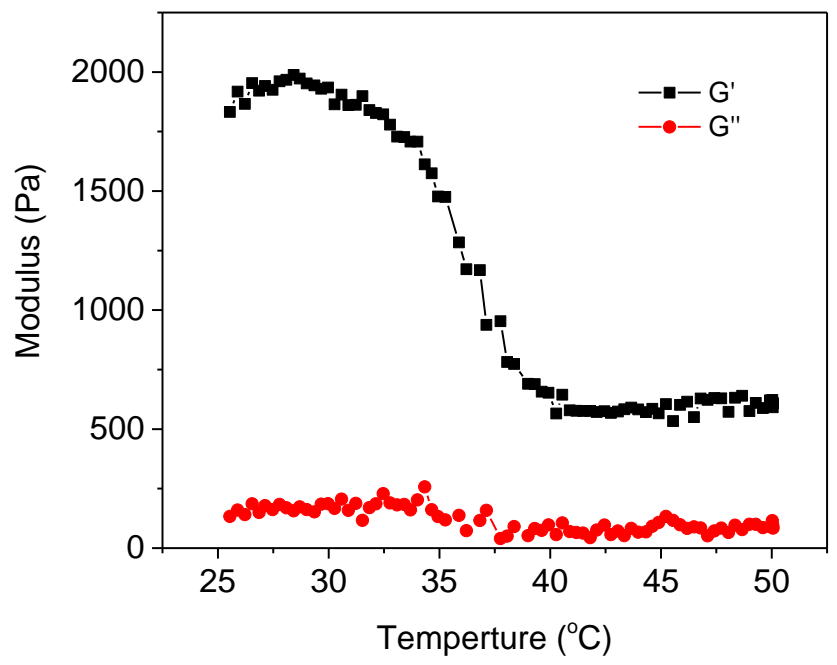

Figure S10. Temperature sweep of GEL1. 


\begin{tabular}{|c|c|c|c|c|c|c|}
\hline Entry & $\mathrm{pH}$ & gelator & P1/PEGDA & hydrazine & gel & \\
\hline & & concentration & (wt/wt) & /aldehyde & formation ${ }^{a}$ & \\
\hline & & (wt\%) & & $(\mathrm{mol} / \mathrm{mol})$ & & \\
\hline 1 & 2 & 15 & $2: 1$ & $2.10: 1$ & + & GEL1 \\
\hline 2 & 2 & 10 & $2: 1$ & $2.10: 1$ & + & GEL2 \\
\hline 3 & 4 & 15 & $2: 1$ & $2.10: 1$ & + & GEL3 \\
\hline 4 & 2 & 7.5 & $2: 1$ & $2.10: 1$ & - & \\
\hline 5 & 4 & 10 & $2: 1$ & $2.10: 1$ & - & \\
\hline 6 & 4 & 20 & $2: 1$ & $2.10: 1$ & + & GEL4 \\
\hline 7 & 2 & 10 & $3: 1$ & $3.15: 1$ & $+($ weak) & \\
\hline 8 & 2 & 10 & $1: 1$ & $1.05: 1$ & - & \\
\hline
\end{tabular}

a plus sign represent hydrogel, minus sign represent solution.

Synthesis of compound 2. $\mathrm{SOCl}_{2}(6.07 \mathrm{~mL}, 0.08 \mathrm{~mol})$ was slowly dropped into $\mathrm{MeOH}(30 \mathrm{~mL})$ in ice bath, and then nitrilotriacetic acid 1 (4 g, $0.02 \mathrm{~mol})$ was added. After $30 \mathrm{~min}$ of stirring in ice bath, the mixture turned clear. The clear solution was stirred continuously for $2 \mathrm{~h}$ at r.t. After removal of $\mathrm{MeOH}$ in vacuo, the residue was dissolved in $\mathrm{DCM}$ and washed sequentially with saturated $\mathrm{NaHCO}_{3}$. A colorless oil liquid was obtained (2.56 g, 52\%). ${ }^{1} \mathrm{H} \mathrm{NMR}\left(\mathrm{CDCl}_{3}, 500 \mathrm{MHz}\right): \delta=3.71\left(\mathrm{~s}, 9 \mathrm{H}, \mathrm{CH}_{3}\right), 3.67\left(\mathrm{~s}, 6 \mathrm{H}, \mathrm{CH}_{2}\right)$.

Synthesis of $\mathbf{B}_{3}$ monomer. Compound $2(2.0 \mathrm{~g}, 8.58 \mathrm{mmol})$ and $\mathrm{N}_{2} \mathrm{H}_{4} \bullet \mathrm{H}_{2} \mathrm{O}(4.4 \mathrm{~mL}, 107.80 \mathrm{mmol})$ were added into $\mathrm{MeOH}(20 \mathrm{~mL})$, then the mixture was stirred under refluxing overnight. The solution was concentrated under reduced pressure. The residue was dissolved in water. The resulting solution was lyophilized. A yellow solid was obtained (1.98 g, 99\%). ${ }^{1} \mathrm{H}$ NMR (DMSO-d, $\left.500 \mathrm{MHz}\right) \delta: 9.27(\mathrm{~s}, 3 \mathrm{H}, \mathrm{NH}), 4.26\left(\mathrm{br}, 6 \mathrm{H}, \mathrm{NH}_{2}\right), 3.17(\mathrm{~s}$, $6 \mathrm{H}, \mathrm{CH}_{2}$ ). ${ }^{13} \mathrm{C}$ NMR (DMSO- $d_{6}, 125 \mathrm{MHz}$ ) $\delta: 169.27,57.37$. HR-MS (MALDI): $\mathrm{m} / \mathrm{z}$ calcd. for $\mathrm{C}_{6} \mathrm{H}_{15} \mathrm{~N}_{7} \mathrm{O}_{3}[\mathrm{M}+\mathrm{Na}]^{+}$ 256.1140; found 256.1128 . 